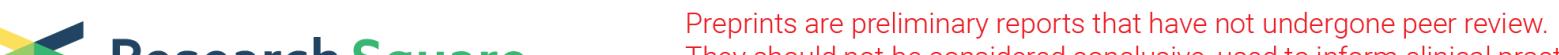 Research Square They should not be considered conclusive, used to inform clinical practice, or referenced by the media as validated information.
}

\section{Comparison of the drug retention and reasons for discontinuation of Tumor Necrosis Factor Inhibitors and Interleukin-6 Inhibitors in patients with Elderly- onset Rheumatoid Arthritis-the ANSWER cohort study}

Sadao Jinno ( $\square$ sadaoj@gmail.com )

Kobe Daigaku https://orcid.org/0000-0003-3021-183X

\section{Akira Onishi}

Kobe Daigaku Byoin: Kobe Daigaku Igakubu Fuzoku Byoin

Maureen Dubreuil

Boston University School of Medicine

Motomu Hashimoto

Kyoto Daigaku Daigakuin Igaku Kenkyuka Igakubu

Wataru Yamamoto

Kyoto Daigaku Daigakuin Igaku Kenkyuka Igakubu

Koichi Murata

Kyoto Daigaku Daigakuin Igaku Kenkyuka Igakubu

Tohru Takeuchi

Osaka Medical College: Osaka Ika Daigaku

Takuya Kotani

Osaka Medical College: Osaka Ika Daigaku

\section{Yuichi Maeda}

Osaka University School of Medicine Graduate School of Medicine: Osaka Daigaku Daigakuin Igakukei Kenkyuka Igakubu

\section{Kosuke Ebina}

Osaka University School of Medicine Graduate School of Medicine: Osaka Daigaku Daigakuin Igakukei Kenkyuka Igakubu

\section{Yonsu Son}

\section{Kansai Ika Daigaku}

\section{Hideki Amuro}

Kansai Ika Daigaku

Ryota Hara 
Nara Medical University School of Medicine Graduate School of Medicine: Nara Kenritsu Ika Daigaku Igakubu Igakuka Daigakuin Igaku Kenkyuka

\section{Masaki Katayama}

Osaka Red Cross Hospital: Osaka Sekijuji Byoin

\section{Jun Saegusa}

Kobe University Graduate School of Medicine School of Medicine: Kobe Daigaku Daigakuin Igakukei Kenkyuka Igakubu

\section{Research article}

Keywords: ANSWER cohort, Biological disease-modifying antirheumatic drugs, Drug retention, Elderly onset rheumatoid arthritis

Posted Date: December 17th, 2020

DOl: https://doi.org/10.21203/rs.3.rs-129417/v1

License: (c) (1) This work is licensed under a Creative Commons Attribution 4.0 International License. Read Full License

Version of Record: A version of this preprint was published at Arthritis Research \& Therapy on April 15th, 2021. See the published version at https://doi.org/10.1186/s13075-021-02496-w. 


\section{Abstract}

Background: This multi-center, retrospective study aimed to clarify retention rates and reasons for discontinuation of either Tumor Necrosis Factor inhibitors (TNFi) or Interleukin-6 Inhibitors (IL-6i) in patients with elderly-onset rheumatoid arthritis (EORA).

Methods: Patients with rheumatoid arthritis (RA) enrolled in a Japanese multicenter observational registry between 2011 and 2020 were included. EORA was defined as RA with onset at 60 or over. To adjust confounding by indication for treatment with TNFi or IL-6i, a propensity score based on multiple baseline characteristics variables was used to compare the drug retention and causes for discontinuation between TNFi and IL-6i. Adjusted cumulative incidence of drug discontinuation for each reason was compared between the two groups using the Fine-Gray model.

Results: Among a total of 9550 patients in the registry, 674 TNFi and 297 IL-6i initiators with EORA were identified. Age, the proportion of females, disease duration, and baseline disease activity at the time of TNFi or IL-6i initiation were similar between the two groups. After adjusting for differences in baseline characteristics between the two groups, overall drug discontinuation was significantly lower in the IL-6i as compared to the TNFi $(\mathrm{HR}=0.71,95 \% \mathrm{Cl}=0.59-0.86, \mathrm{p}<0.001)$. The adjusted cumulative incidence of discontinuation due to lack of effectiveness was lower with the IL-6i $(\mathrm{HR}=0.46,95 \% \mathrm{Cl}=0.33-0.63$, $\mathrm{p}<0.001)$ while those due to adverse events $(\mathrm{HR}=0.82,95 \% \mathrm{Cl}=0.56-1.18, \mathrm{p}=0.28)$ or achievement of clinical remission $(\mathrm{HR}=1.09,95 \% \mathrm{Cl}=0.62-1.91, \mathrm{p}=0.76)$ were similar between the two groups.

Conclusions: In EORA patients initiating a TNFi or IL-6i, significantly higher drug retention was observed with IL-6i. Discontinuation due to lack of effectiveness was significantly less frequent in IL-6i while discontinuations due to adverse event or achievement of clinical remission were similar between the two groups.

\section{Introduction}

Rheumatoid arthritis (RA) among elderly people is an increasingly important health concern. A recent large RA registry in the United States showed that approximately one-fourth of the enrolled patients were diagnosed after the age of 60 years [1]. In a Swiss prospective observational cohort for early RA and undifferentiated arthritis (disease duration after the first symptom $<1$ year), the peak age at disease onset was between 50 and 60 years and was $\geq 60$ years in $38.2 \%$ of the 592 patients [2]. In Japan, where the population has aged rapidly in recent decades, one of the large registry studies showed the peak age at onset of RA has shifted from 50-59 to 60-69 years of age over the past decade [3]. In fact, it is not uncommon to see patients who develop RA over the age of 70 or even 80 in a typical Japanese rheumatology practice.

Elderly onset-rheumatoid arthritis (EORA) is usually defined as disease onset after 60 years of age [4]. Patients with elderly-onset rheumatoid arthritis (EORA) can present with higher disease activity at urden of comorbidities than those with young-onset 
rheumatoid arthritis (YORA) [4-7]. It is not entirely clear why these discrepancies arise between the two age groups, but one study reported EORA patients had higher IL-6 levels and lower TNF- alpha levels as compared to YORA patients [8]. Furthermore, previous studies showed the distribution of the human leukocyte antigen-DRB1 genotypes were different between EORA and YORA $[9,10]$. These findings suggest different cytokines may be involved in pathogenesis between the two age groups.

With a potentially growing number of EORA patients who may have a different cytokine profile from YORA patients, it is imperative to know which biologic disease modifying anti-rheumatic drugs (bDMARDs) can be used more effectively and safely among them. However, there have been no randomized controlled trials comparing the efficacy and safety of different bDMARDs among EORA patients. Randomized controlled trials primarily recruit healthy or single-disease volunteers rather than elderly patients or those with comorbidities [11]. Thus, cohort-based observational studies may be more suitable to investigate the performance of bDMARDs among unique population such as EORA. There have been a few observational studies comparing the effectiveness of bDMARDs among elderly patients with RA $[12,13]$. These studies included not only EORA but young-onset RA who had relatively long disease duration.

Given that drug retention can be a proxy to both safety and effectiveness of bDMARDs [14-16], we hypothesized comparison of drug retention is a reasonable way to assess the efficacy and safety of bDMARDs among EORA patients. The objective of the study was to investigate drug retention and reasons for discontinuation of TNFi and IL-6i among EORA by utilizing the data from multicenter observational cohort in Japan.

\section{Methods}

Study design and data source. The Kansai Consortium for Well-being of Rheumatic Disease Patients (ANSWER) cohort is an observational multi-center registry of patients with RA in the Kansai district of Japan. Data from patients at seven institutes (Kyoto University, Osaka University, Osaka Medical College, Kansai Medical University, Kobe University, Nara Medial University, and Osaka Red Cross Hospital) were included. ANSWER is an ongoing prospective cohort study of adult patients with RA [13,17]. Serial disease assessments including laboratories and treatment history were recorded. The data from 2011 to 2020 were retrospectively analyzed. In this study, we included all patients whose RA onset was at age 60 or over. Patients with RA fulfilled the 1987 American College of Rheumatology (ACR) or 2010 ACR/European League Against Rheumatism (EULAR) criteria. Patients were treated according to the Japan College of Rheumatology guideline [18], similar to the EULAR and ACR guidelines, first with a conventional synthetic DMARD (cSDMARD), primarily methotrexate with or without glucocorticoids, followed by the addition of bDMARDs or other csDMARDs, using the treat-to-target approach $[19,20]$. This study used data on the following bDMARDs: TNFi (adalimumab, certolizumab pegol, etanercept, golimumab, infliximab), and IL-6i (tocilizumab or sarilumab). Baseline demographic data including age, sex, tender joint count, swollen joint count, patient global assessment (PtGA), physician global 
rate [DAS28-ESR], clinical disease activity index [CDAI], and simple disease activity index [SDAI]), disease duration of RA, current bDMARD use, number of previously administered bDMARDs, reasons for discontinuation of bDMARDs, dates of both starting and discontinuing bDMARDs, concomitant use of methotrexate, glucocorticoids, sulfasalazine, and other csDMARDs such as leflunomide, bucillamine, iguratimod, and tacrolimus were collected. Other baseline demographic features such as baseline Creactive protein (CRP), rheumatoid factor (RF) and anti-cyclic citrullinated peptide antibody (ACPA) positivity, and Health Assessment Questionnaire disability index (HAQ-DI) score were also collected. Baseline demographic data was collected within 90 days prior to the date each bDMARD was initiated while baseline disease activity was measured at the time of bDMARD initiation. We have included all treatment with bDMARDs in each patient and reflected in the number of previously administrated bDMARDs.

Outcome of interest. The primary outcome of interest, drug retention after initiation of TNFi or IL-6i, was evaluated using the time until definitive treatment discontinuation. Temporary discontinuations followed by reintroduction of the same medication were not recorded as discontinuations. As a part of requirement for cohort participation, physicians were mandated to report a reason for discontinuation of bDMARDs. The reasons for discontinuation were as follows: drug inefficacy, achievement of clinical remission, toxic adverse events, patient preference (including financial reasons), loss to follow up, and other. The secondary outcomes included adjusted cumulative incidence of specific reasons for drug discontinuation: lack of effectiveness, adverse events, or RA remission after initiation of a TNFi or IL-6i.

The study was approved by the ethics committee of Kobe University (approval number 1738) as well as the ethics committees of all participating institutions. The study was conducted in accordance with the Declaration of Helsinki. In our institute, the institutional review board waived the requirement for patients' informed consent because this study utilized only existing data collected in clinical practice. The opportunity to refuse participation in the research was ensured for the research subjects. The study was approved by the institutional review board of all 7 institutes.

Statistical Analysis. A propensity score approach was used to account for differences in potential confounding factors. A propensity score was recalculated at the time of initiating each bDMARD. A logistic regression model was used to calculate the propensity score defined as the probability of initiation of TNFi or IL-6i based on patient covariates. Prespecified potential confounding factors and predictors of the outcome were age, sex, RA duration, baseline CDAl, RF or ACPA positivity, concomitant glucocorticoid, methotrexate, sulfasalazine and other csDMARDs, and number of previously administered bDMARDs [21-24]. The analyses were based on inverse probability of treatment weighting to reduce the variability of weights and standard errors of estimated treatment effects. We used the Cox proportional model for the primary outcome, bDMARD retention, and the Fine-Gray hazard competing risk regression model for adverse events, lack of effectiveness, and remission, and accounted for clustering effects by individual [25]. To account for missing data, we used multiple imputations by a chained equation, using all other variables to impute any missing values for variables included in the logistic regression model. 
logistic model and pooled the resulting parameters according to Rubin's rules [26]. Lastly, we performed the Cox proportional model for bDMARD retention among those who did not respond to initial TNFi as a subgroup analysis. Statistical analyses were performed using SAS version 9.3 and STATA version 13.1 (StataCorp, Texas, USA). P $<0.05$ were considered statistically significant.

\section{Results}

Patient Characteristics. The study population was selected from all patients with RA in the ANSWER cohort $(n=9,550)$ who fulfilled the inclusion criteria during the study period. A total of 674 TNFi and 297 IL-6i initiators with EORA were identified. Baseline demographics, disease characteristics, and concomitant therapies were mostly similar between the groups (Table 1). The median age of EORA at the time of TNFi or IL-6i initiation was similar. The proportion of females was similar between the two groups. The median disease duration was slightly longer in the IL-6i initiators. The median CRP was significantly higher in the IL-6i initiators. The percentage of RF and ACPA positivity was similar between the two groups. Baseline DAS28-ESR, SDAI, and CDAI, and HAQ-DI score were similar between the two groups. Methotrexate usage was less frequent in the IL-6i initiators. Glucocorticoid usage was more frequent in the IL-6i. Sulfasalazine usage was similar while other csDMARDs usage was more frequent in the IL-6i. The TNFi group received bDMARDs as the first agent more frequently as compared to the IL-6i. Of the TNFi-treated patients, 177 (26.3\%) initiated etanercept, 114 (16.9\%) adalimumab, 83 (12.3\%) certolizumab pegol, 62 (9.2\%) infliximab, and 238 (35.3\%) golimumab. Of the IL-6i treated patients, 272 $(91.6 \%)$ initiated tocilizumab, and $25(8.4 \%)$ sarilumab.

Drug retention and specific causes for discontinuation. The median follow-up duration was 418 days in the TNFi and 497 days in the IL-6i. After adjustment for other confounders, IL-6i use was associated with significantly lower overall drug discontinuation as compared to the TNFi $(\mathrm{HR}=0.71,95 \% \mathrm{Cl}=0.59-0.86, \mathrm{p}$ $<0.001$ ) (Fig. 1A). Adjusted cumulative incidence of drug discontinuation for each specific cause was compared between the two groups. The incidence of drug discontinuation due to lack of effectiveness was significantly lower in the IL-6i group $(\mathrm{HR}=0.46,95 \% \mathrm{Cl}=0.33-0.63, \mathrm{p}<0.001)$ (Fig. 1B). The incidence of drug discontinuation due to adverse event $(\mathrm{HR}=0.82,95 \% \mathrm{Cl}=0.56-1.18, \mathrm{p}=0.28)$ and clinical remission $(\mathrm{HR}=1.09,95 \% \mathrm{Cl}=0.62-1.91, \mathrm{p}=0.76)$ were similar between the two groups after adjustment for the confounders (Fig. 1C and 1D). Furthermore, we performed a subgroup analysis among EORA patients who did not respond to initial TNFi $(n=197)$. IL-6i $(n=106)$ use was associated with significantly lower overall drug discontinuation as compared to TNFi $(n=91)(\mathrm{HR}=0.62,95 \% \mathrm{Cl}=0.41-$ $0.92, p=0.02$ ).

\section{Discussion}

In this analysis of a large Japanese RA registry, overall drug discontinuation and discontinuation specifically due to lack of effectiveness were significantly lower in the IL-6i as compared to the TNFi. Discontinuations due to adverse event or achievement of clinical remission were similar between the two 
groups. To the best of our knowledge, this is the first report in the real-world setting comparing the drug retention and reasons for discontinuation between TNFi and IL-6i among persons with EORA.

Patients who initiated IL-6i in the present study had longer drug retention than those who initiated TNFi, which may be related to differences observed in clinical effectiveness. In fact, drug discontinuation due to lack of clinical effectiveness was significantly lower in the IL-6i group. The reasons for the difference are considered as follows. First, EORA patients could have inflammation mainly driven by high IL-6 levels, indicating blocking IL- 6 is a reasonable way of reducing an inflammatory cascade among EORA patients. In the present study, the median baseline CRP was significantly higher in the IL-6i as compared to the TNFi (1.74 mg/dL versus $1.02 \mathrm{mg} / \mathrm{dL} ; \mathrm{p}=0.02)$. Several studies have found RA patients with high IL-6 levels had a greater response to IL-6i compared to TNFi [27-30]. Most recently, a post hoc analysis by Boyapati et al evaluated whether baseline IL-6 levels are predictive of sarilumab treatment responses in 2 phase III studies [29]. Patients with high baseline IL-6 levels (all $\geq 3$ times the upper limit of normal; $n=$ 100) had higher disease activity at baseline than those with low IL-6 levels $(n=100)$. The magnitude of clinical improvement over 24 weeks with sarilumab versus adalimumab was greater in patients with high compared to those with low baseline IL-6 levels. Second, EORA patients often have large joint involvement associated with higher serological inflammatory markers and more functional disabilities [4-7]. In such cases, agents that effectively control large joints inflammation would be a reasonable option. A group from Japan compared the efficacy of IL-6i with TNFi in the treatment of RA patients who have knee joint involvement [31]. The patients who had knee joint involvement and were treated with an IL-6i had greater improvement of CDAl from baseline $(n=95, \triangle$ CDAI $15.0 \pm 10.8$; mean \pm SD) compared to those treated with TNFi $(n=148, \triangle$ CDAl $11.4 \pm 10.3$; mean $\pm S D)$ at 12 weeks $(P=0.003)$. These findings suggest IL-6i may be more effective in EORA patients, especially with large joint involvement. Additionally, EORA patients may have concurrent renal insufficiency that could limit the use of methotrexate cotherapy. EORA patients also may not tolerate methotrexate due to comorbidities or adverse events. In a Canadian population-based study, increasing age was associated with an increased tendency towards methotrexate discontinuation in newly diagnosed RA patients [32]. Hence, bDMARD monotherapy may be necessary in EORA patients. In such cases, IL-6i may be a better approach than TNFi based on its efficacy without concurrent methotrexate therapy [33].

Previous studies that compared the efficacy of TNFi with IL-6i were primarily based on patients with YORA. The randomized controlled phase IV ADACTA trial in patients with RA (mean age 53) who were intolerant of methotrexate or for whom continued therapy with methotrexate was inappropriate demonstrated superiority of tocilizumab monotherapy over adalimumab monotherapy for change in the DAS28-ESR from baseline to week 24 [33]. More tocilizumab-treated than adalimumab-treated patients achieved remission according to the DAS28-ESR (DAS28 < 2.6) and the CDAI (CDAI $\leq 2.8)$. More recently, a prospective, observational, comparative effectiveness study involving 1216 patients (mean age 54) who initiated TNFi or tocilizumab as their first bDMARDs demonstrated change from baseline in CDAI was greater with tocilizumab (adjusted mean difference: week 24, -3.48; week 52, -4.60; both $p<0.001$ ) [34]. On the other hand, network meta-analyses of randomized controlled trial data investigating relative Loading [MathJax]/jax/output/CommonHTML/jax.js :ults [35-37]. Comparable ACR response rates have been 
found between tocilizumab and TNFi agents in combination with DMARDs, which could be due to differences in the population and outcome definition.

A subgroup analysis showed IL-6i was associated with significantly higher drug retention as compared to a TNFi among EORA patients who did not respond to initial TNFi, suggesting agents with another mode of action such as IL-6i may be more effective than a second TNF among initial TNFi non-responders. Our results are in support of other reports on YORA patients that demonstrated better efficacy using an agent with another mode of action rather than a second TNFi [38-40]. These results suggest treatment for initial TNFi non-responders among EORA patients should be agents with another mode of action rather than a second TNFi.

Adverse event discontinuation was similar between the TNFi and IL-6i in our population. Our results are in support of a previous observational study that reported a similar safety profile between the two medication classes [41-43]. A propensity score-matched study using large claims data from US Medicare found that the risk of severe infections was not different between tocilizumab and TNFi initiators (combined HR 1.05, 95\% $\mathrm{Cl} 0.95$ to 1.16) [41]. Other studies evaluating the safety profile between the two agents were mostly based on RA patients younger than 60 year of age. A prospective cohort study using a Japanese RA registry showed no significant difference in the severe infection rate with tocilizumab versus TNFi use (HR 2.23, 95\% $\mathrm{Cl} 0.93$ to 5.37) [42]. On the other hand, an observational cohort study using data from the British Society for Rheumatology Biologics Register for Rheumatoid Arthritis showed an increased risk (HR 1.22, 95\% Cl 1.02 to 1.47) in tocilizumab compared with etanercept for severe infection, defined as an infection resulting in death, hospitalization or requiring intravenous antimicrobial therapy [44]. Such discrepancies could arise from differences in study population, comparison group and outcome definition. Our study, along with another study that investigated the safety of IL-6i among elderly RA population [41], provides additional data to the literature that IL-6i therapy is generally well tolerated among them. Patient-specific risk factors such as comorbidities may be more important on the risk of severe infection than the choice of bDMARDs between TNFi and IL-6i [43].

The present study had some limitations. First, comorbidities such as diabetes mellitus or respiratory diseases were not adjusted as confounders between the two groups since the registry does not include comorbidities information. Healthier patients could be selected more frequently for IL-6i treatment as compared to TNFi (or vice versa). However, we have adjusted for available confounders such as disease duration, baseline disease activity, or concomitant use of glucocorticoids between the two groups. Second, the judgment and reasons for discontinuation (such as lack of effectiveness or remission) depended on the decisions of each physician without standardized criteria. Third, the difference between intravenous and subcutaneous bDMARDs could not be determined. Fourth, the study population was predominantly Japanese. Our results may not be generalizable to other patient populations due to differences in patient factors or practice patterns. Fifth, number of previously administrated bDMARDs. Lastly, drug retention was used for outcome assessments in the present study while response criteria remain standard outcome measures for clinical trials. 
The strengths of this study include the use of data from a large multi-center cohort of EORA patients with prospectively collected detailed longitudinal clinical data including both clinical outcomes and adverse events. We used sophisticated statistical models adjusting for potential confounders using inverse probability of treatment weighting and the Fine-Gray hazard competing risk regression model.

In conclusion, in EORA patients initiating a TNFi or IL-6i, significantly higher drug retention was observed with IL-6i. Discontinuation due to lack of effectiveness was significantly lower with IL-6i while discontinuations due to an adverse event or achievement of clinical remission were similar between the two groups. Further investigation is warranted in other datasets to draw more conclusive estimates on the comparative effectiveness and safety of bDMARDs in patients with EORA.

\section{Declarations}

\section{Ethics approval and consent to participate}

This observational study was conducted as per the Declaration of Helsinki. The study was approved by the ethics committee of Kobe University (approval number 1738) as well as the ethics committees of all participating institutions. In our institute, the institutional review board waived the requirement for patients' informed consent because this study utilized only existing data collected in clinical practice. The opportunity to refuse participation in the research was ensured for the research subjects.

\section{Funding}

The study reported in this publication uses ANSWER Cohort supported by grants from eight pharmaceutical companies (AbbVie G.K., Asahi Kasei Pharma, Ayumi Pharmaceutical Co., Chugai Pharmaceutical Co., Ltd., Eisai Co., Ltd., Janssen Pharmaceutical K.K., Ono Pharmaceutical Co., and Sanofi) and an information technology services company (CAC). This study is conducted as an investigator initiated study. These companies have no roles in study design, data collection, data analysis, data interpretation or writing of the report.

\section{Competing interests}

Sadao Jinno has received speaking fees from AbbVie G.K., Asahi Kasei Pharma., Bristol-Myers Squibb., Chugai Pharmaceutical Co., Ltd., Eisai Co., Ltd., Eli Lilly Japan K.K., Janssen Pharmaceutical K.K., and Mitsubishi Tanabe Pharma, and Ono Pharmaceutical Co.. Akira Onishi reports grants from Advantest, personal fees from Asahi Kasei Pharma, Chugai Pharmaceutical Co., Ltd., Eli Lilly Japan K.K, Ono Pharmaceutical Co., Mitsubishi Tanabe Pharma, Takeda Pharmaceutical Company Limited, and Daiichi Sankyo Co. Ltd. Maureen Dubreuil has served on Advisory board for UCB Inc.. Motomu Hashimoto and Koichi Murata belong to the department that is financially supported by five pharmaceutical companies (Tanabe-Mitsubishi, Chugai, Ayumi, UCB-Japan and Asahi-Kasei), Nagahama city and Toyooka city. Motomu Hashimoto has received speaking fees from Mitsubishi Tanabe Pharma and Bristol-Myers 
received a speaking fee and/or consulting fee from Eisai Co., Ltd.. Tohru Takeuchi has received grants from Chugai Pharmaceutical Co. Ltd, personal fees from Astellas Pharma Inc, Chugai Pharmaceutical Co. Ltd, Mitsubishi Tanabe Pharma Corporation, AbbVie GK, Bristol Myers Squibb, Ayumi Pharmaceutical Co., Daiichi Sankyo Co. Ltd, Eisai Co. Ltd, Takeda Pharmaceutical Co. Ltd, and Asahi Kasei Pharma. Yuichi Maeda received a research grant and/or speaker fee from Eli Lilly Japan K.K., Chugai Pharmaceutical Co. Ltd., Pfizer Inc., Bristol Myers Squibb, and Mitsubishi Tanabe Pharma Corporation. Kosuke Ebina is affiliated with the Department of Musculoskeletal Regenerative Medicine, Osaka University, Graduate School of Medicine, which is supported by Taisho. Kosuke Ebina has received research grants from AbbVie G.K., Asahi Kasei Pharma., Astellas Pharma Inc., Chugai Pharmaceutical Co., Ltd., Eisai Co., Ltd., Mitsubishi Tanabe Pharma Corporation, Ono Pharmaceutical, Teijin Pharma, and UCB Japan. Kosuke Ebina has received payments for lectures from Abbie G.K., Asahi Kasei Pharma Corporation, Astellas Pharma Inc., Ayumi Pharmaceutical Co., Bristol-Myers Squibb, Chugai Pharmaceutical Co. Ltd., Eisai Co., Ltd., Janssen Pharmaceutical K.K., Mitsubishi Tanabe Pharma Corporation, Ono Pharmaceutical, Pfizer Inc., Sanofi, and UCB Japan. Yonsu Son has received speaking fees from Actelion, Bristol-Myers Squibb., Chugai Pharmaceutical Co., Ltd., Eisai Co., Ltd., and Mitsubishi Tanabe Pharma, and Sanofi K.K.. Hideki Amuro has received speaking fees from Asahi Kasei Pharma Corporation, Mitsubishi Tanabe Pharma Corporation, Astellas Pharma Inc., and Novartis Pharma KK. Ryota Hara has received speaking fees from AbbVie G.K.. Jun Saegusa has received speaking fees from AbbVie G.K., Asahi Kasei Pharma., Eli Lilly Japan K.K. and Janssen Pharmaceutical K.K.. All other authors have declared no conflicts of interests.

\section{Acknowledgments}

We wish to thank all medical staff at all institutions participating in the ANSWER cohort for providing the data.

\section{Author contributions}

Conceived and designed the study: SJ, AO. Analyzed the data: SJ, AO, and MD. Collection of data: SJ, AO, $\mathrm{MH}, \mathrm{WY}, \mathrm{KM}, \mathrm{TT}, \mathrm{TK}, \mathrm{YM}, \mathrm{KE}, \mathrm{YS}, \mathrm{HA}, \mathrm{RH}, \mathrm{MK}$, and JS. SJ prepared the initial draft of the manuscript. All the authors were involved in revising the manuscript critically for content. All authors read and approved the final manuscript.

\section{Data availability}

The datasets generated and/or analyzed during the current study are not publicly available. Patients did not provide consent for raw data sharing during the data collection. All aggregated data relevant to the study are included in the article or uploaded as supplementary information.

\section{References}

1. Koller MD, Aletaha D, Funovits J, Pangan A, Baker D, Smolen JS. Response of elderly patients with Loading [MathJax]/jax/output/CommonHTML/jax.js 
Rheumatology. 2009;48(12):1575-80.

2. Mueller RB, Kaegi T, Finckh A, Haile SR, Schulze-Koops H, von Kempis J. SCQM physicians: Is radiographic progression of late-onset rheumatoid arthritis different from young-onset rheumatoid arthritis? Results from the Swiss prospective observational cohort. Rheumatology. 2014;53(4):6717.

3. Kato E, Sawada T, Tahara K, Hayashi H, Tago M, Mori H, Nishino J, Matsui T, Tohma S. The age at onset of rheumatoid arthritis is increasing in Japan: a nationwide database study. Int J Rheum Dis. 2017;20(7):839-45.

4. Deal CL, Meenan RF, Goldenberg DL, Anderson JJ, Sack B, Pastan RS, Cohen AS. The clinical features of elderly-onset rheumatoid arthritis. A comparison with younger-onset disease of similar duration. Arthritis Rheum. 1985;28(9):987-94.

5. van der Heijde DM, van Riel PL, van Leeuwen MA, van 't Hof MA, van Rijswijk MH, van de Putte, L B: Older versus younger onset rheumatoid arthritis: results at onset and after 2 years of a prospective followup study of early rheumatoid arthritis. J Rheumatol 1991, 18(9):1285-1289.

6. Murata K, Ito H, Hashimoto M, Nishitani K, Murakami K, Tanaka M, Yamamoto W, Mimori T, Matsuda S. Elderly onset of early rheumatoid arthritis is a risk factor for bone erosions, refractory to treatment: KURAMA cohort. Int J Rheum Dis. 2019;22(6):1084-93.

7. Innala L, Berglin E, Moller B, Ljung L, Smedby T, Sodergren A, Magnusson S, Rantapaa-Dahlqvist S, Wallberg-Jonsson S. Age at onset determines severity and choice of treatment in early rheumatoid arthritis: a prospective study. Arthritis Res Ther. 2014;16(2):R94.

8. Chen DY, Hsieh TY, Chen YM, Hsieh CW, Lan JL, Lin FJ. Proinflammatory cytokine profiles of patients with elderly-onset rheumatoid arthritis: a comparison with younger-onset disease. Gerontology. 2009;55(3):250-8.

9. Oka S, Furukawa H, Shimada K, Hashimoto A, Komiya A, Tsunoda S, Saisho K, Tsuchiya N, Katayama M, Shinohara S, Matsui T, Fukui N, Sano H, Migita K, Tohma S. Association of HLA-DRB1 genotype with younger age onset and elder age onset rheumatoid arthritis in Japanese populations. Med (Baltim). 2019;98(48):e18218.

10. Hellier JP, Eliaou JF, Daures JP, Sany J, Combe B. HLA-DRB1 genes and patients with late onset rheumatoid arthritis. Ann Rheum Dis. 2001;60(5):531-3.

11. Grimes DA, Schulz KF. Bias and causal associations in observational research. Lancet. 2002;359(9302):248-52.

12. Kawabe A, Nakano K, Kubo S, Asakawa T, Tanaka Y. Differential long-term retention of biological disease-modifying antirheumatic drugs in patients with rheumatoid arthritis by age group from the FIRST registry. Arthritis Res Ther. 2020;22(1):136-020.

13. Ebina K, Hashimoto M, Yamamoto W, Ohnishi A, Kabata D, Hirano T, Hara R, Katayama M, Yoshida S, Nagai K, Son Y, Amuro H, Akashi K, Fujimura T, Hirao M, Yamamoto K, Shintani A, Kumanogoh A, Yoshikawa H. Drug retention and discontinuation reasons between seven biologics in patients with 
14. Simard JF, Arkema EV, Sundstrom A, Geborek P, Saxne T, Baecklund E, Coster L, Dackhammar C, Jacobsson L, Feltelius N, Lindblad S, Rantapaa-Dahlqvist S, Klareskog L, van Vollenhoven RF, Neovius M, Askling J. Ten years with biologics: to whom do data on effectiveness and safety apply? Rheumatology. 2011;50(1):204-13.

15. Hyrich KL, Watson KD, Lunt M, Symmons DP, British Society for Rheumatology Biologics Register (BSRBR). Changes in disease characteristics and response rates among patients in the United Kingdom starting anti-tumour necrosis factor therapy for rheumatoid arthritis between 2001 and 2008. Rheumatology. 2011;50(1):117-23.

16. Neovius M, Arkema EV, Olsson H, Eriksson JK, Kristensen LE, Simard JF, Askling J, ARTIS Study Group. Drug survival on TNF inhibitors in patients with rheumatoid arthritis comparison of adalimumab, etanercept and infliximab. Ann Rheum Dis. 2015;74(2):354-60.

17. Hashimoto M, Furu M, Yamamoto W, Fujimura T, Hara R, Katayama M, Ohnishi A, Akashi K, Yoshida S, Nagai K, Son Y, Amuro H, Hirano T, Ebina K, Uozumi R, Ito H, Tanaka M, Ohmura K, Fujii T, Mimori T. Factors associated with the achievement of biological disease-modifying antirheumatic drug-free remission in rheumatoid arthritis: the ANSWER cohort study. Arthritis Res Ther. 2018;20(1):165-018.

18. Kawahito Y. Guidelines for the management of rheumatoid arthritis. Nihon Rinsho. 2016;74(6):93943.

19. Singh JA, Saag KG, Bridges SL, AkI EA, Bannuru RR, Sullivan MC, Vaysbrot E, McNaughton C, Osani M, Shmerling RH, Curtis JR, Furst DE, Parks D, Kavanaugh A, O'Dell J, King C, Leong A, Matteson EL, Schousboe JT, Drevlow B, Ginsberg S, Grober J, St Clair EW, Tindall E, Miller AS, McAlindon T, American College of Rheumatology. 2015 American College of Rheumatology Guideline for the Treatment of Rheumatoid Arthritis. Arthritis Care Res (Hoboken). 2016;68(1):1-25.

20. Smolen JS, Landewe RBM, Bijlsma JWJ, Burmester GR, Dougados M, Kerschbaumer A, McInnes IB, Sepriano A, van Vollenhoven RF, de Wit M, Aletaha D, Aringer M, Askling J, Balsa A, Boers M, den Broeder AA, Buch MH, Buttgereit F, Caporali R, Cardiel MH, De Cock D, Codreanu C, Cutolo M, Edwards CJ, van Eijk-Hustings Y, Emery P, Finckh A, Gossec L, Gottenberg JE, Hetland ML, Huizinga TWJ, Koloumas M, Li Z, Mariette X, Muller-Ladner U, Mysler EF, da Silva JAP, Poor G, Pope JE, Rubbert-Roth A, Ruyssen-Witrand A, Saag KG, Strangfeld A, Takeuchi T, Voshaar M, Westhovens R, van der Heijde D. EULAR recommendations for the management of rheumatoid arthritis with synthetic and biological disease-modifying antirheumatic drugs: 2019 update. Ann Rheum Dis 2020, .

21. Jorgensen TS, Kristensen LE, Christensen R, Bliddal H, Lorenzen T, Hansen MS, Ostergaard M, Jensen J, Zanjani L, Laursen T, Butt S, Dam MY, Lindegaard HM, Espesen J, Hendricks O, Kumar P, Kincses A, Larsen LH, Andersen M, Naeser EK, Jensen DV, Grydehoj J, Unger B, Dufour N, Sorensen V, Vildhoj S, Hansen IM, Raun J, Krogh NS, Hetland ML. Effectiveness and drug adherence of biologic monotherapy in routine care of patients with rheumatoid arthritis: a cohort study of patients registered in the Danish biologics registry. Rheumatology. 2015;54(12):2156-65.

22. Gabay C, Riek M, Scherer A, Finckh A. SCQM collaborating physicians: Effectiveness of biologic DMARDs in monotherapy versus in combination with synthetic DMARDs in rheumatoid arthritis: data Loading [MathJax]/jax/output/CommonHTML/jax.js ment Registry. Rheumatology. 2015;54(9):1664-72. 
23. Favalli EG, Biggioggero M, Marchesoni A, Meroni PL. Survival on treatment with second-line biologic therapy: a cohort study comparing cycling and swap strategies. Rheumatology. 2015;54(7):1337.

24. Du Pan SM, Dehler S, Ciurea A, Ziswiler HR, Gabay C, Finckh A. Swiss Clinical Quality Management Physicians: Comparison of drug retention rates and causes of drug discontinuation between antitumor necrosis factor agents in rheumatoid arthritis. Arthritis Rheum. 2009;61(5):560-8.

25. Scrucca L, Santucci A, Aversa F. Competing risk analysis using R: an easy guide for clinicians. Bone Marrow Transplant. 2007;40(4):381-7.

26. Hughes RA, Sterne J, Tilling K. Comparison of imputation variance estimators. Stat Methods Med Res. 2016;25(6):2541-57.

27. Uno K, Yoshizaki K, Iwahashi M, Yamana J, Yamana S, Tanigawa M, Yagi K. Pretreatment Prediction of Individual Rheumatoid Arthritis Patients' Response to Anti-Cytokine Therapy Using Serum Cytokine/Chemokine/Soluble Receptor Biomarkers. PLoS One. 2015;10(7):e0132055.

28. Wang J, Platt A, Upmanyu R, Germer S, Lei G, Rabe C, Benayed R, Kenwright A, Hemmings A, Martin $M$, Harari O. IL-6 pathway-driven investigation of response to IL-6 receptor inhibition in rheumatoid arthritis. BMJ Open. 2013;3(8):e003199-2013.

29. Boyapati A, Schwartzman S, Msihid J, Choy E, Genovese MC, Burmester GR, Lam G, Kimura T, Sadeh J, Weinreich DM, Yancopoulos GD, Graham NMH. Association of High Serum Interleukin-6 Levels With Severe Progression of Rheumatoid Arthritis and Increased Treatment Response Differentiating Sarilumab From Adalimumab or Methotrexate in a Post Hoc Analysis. Arthritis Rheumato/ 2020, .

30. Shimamoto K, Ito T, Ozaki Y, Amuro H, Tanaka A, Nishizawa T, Son Y, Inaba M, Nomura S. Serum interleukin 6 before and after therapy with tocilizumab is a principal biomarker in patients with rheumatoid arthritis. J Rheumatol. 2013;40(7):1074-81.

31. Maeda Y, Hirano T, Hara R, Ebina K, Hashimoto M, Yamamoto W, Murakami K, Kotani T, Hata K, Son Y, Amuro H, Onishi A, Jinno S, Katayama M, Kumanogoh A. ANTI-IL-6 RECEPTOR ANTIBODY AMELIORATES DISEASE ACTIVITY OF RHEUMATOID ARTHRITIS PATIENTS WITH KNEE JOINT INVOLVEMENT-ANSWER COHORT STUDY[abstract]. Annals of the Rheumatic Diseases 2020, 79:302-303.

32. Bernatsky S, Ehrmann Feldman D. Discontinuation of methotrexate therapy in older patients with newly diagnosed rheumatoid arthritis: analysis of administrative health databases in Quebec. Canada Drugs Aging. 2008;25(10):879-84.

33. Gabay C, Emery P, van Vollenhoven R, Dikranian A, Alten R, Pavelka K, Klearman M, Musselman D, Agarwal S, Green J, Kavanaugh A. ADACTA Study Investigators: Tocilizumab monotherapy versus adalimumab monotherapy for treatment of rheumatoid arthritis (ADACTA): a randomised, doubleblind, controlled phase 4 trial. Lancet. 2013;381(9877):1541-50.

34. Choy EH, Bernasconi C, Aassi M, Molina JF, Epis OM. Treatment of Rheumatoid Arthritis With AntiTumor Necrosis Factor or Tocilizumab Therapy as First Biologic Agent in a Global Comparative Observational Study. Arthritis Care Res (Hoboken). 2017;69(10):1484-94. 
35. Buckley F, Finckh A, Huizinga TW, Dejonckheere F, Jansen JP. Comparative Efficacy of Novel DMARDs as Monotherapy and in Combination with Methotrexate in Rheumatoid Arthritis Patients with Inadequate Response to Conventional DMARDs: A Network Meta-Analysis. J Manag Care Spec Pharm. 2015;21(5):409-23.

36. Orme ME, Macgilchrist KS, Mitchell S, Spurden D, Bird A. Systematic review and network metaanalysis of combination and monotherapy treatments in disease-modifying antirheumatic drugexperienced patients with rheumatoid arthritis: analysis of American College of Rheumatology criteria scores 20, 50, and 70. Biologics 2012, 6:429-464.

37. Guyot P, Taylor P, Christensen R, Pericleous L, Poncet C, Lebmeier M, Drost P, Bergman G. Abatacept with methotrexate versus other biologic agents in treatment of patients with active rheumatoid arthritis despite methotrexate: a network meta-analysis. Arthritis Res Ther. 2011;13(6):R204.

38. Gottenberg JE, Morel J, Perrodeau E, Bardin T, Combe B, Dougados M, Flipo RM, Saraux A, Schaeverbeke T, Sibilia J, Soubrier M, Vittecoq O, Baron G, Constantin A, Ravaud P, Mariette X. French Society of Rheumatology and the investigators participating in AIR, ORA: Comparative effectiveness of rituximab, abatacept, and tocilizumab in adults with rheumatoid arthritis and inadequate response to TNF inhibitors: prospective cohort study. BMJ. 2019;364:167.

39. Gottenberg JE, Brocq O, Perdriger A, Lassoued S, Berthelot JM, Wendling D, Euller-Ziegler L, Soubrier M, Richez C, Fautrel B, Constantin AL, Mariette X, Morel J, Gilson M, Cormier G, Salmon JH, Rist S, Liote F, Marotte H, Bonnet C, Marcelli C, Sellam J, Meyer O, Solau-Gervais E, Guis S, Ziza JM, Zarnitsky C, Chary-Valckenaere I, Vittecoq O, Saraux A, Pers YM, Gayraud M, Bolla G, Claudepierre P, Ardizzone M, Dernis E, Breban MA, Fain O, Balblanc JC, Aberkane O, Vazel M, Back C, Candon S, Chatenoud L, Perrodeau E, Sibilia J, Ravaud P. Non-TNF-Targeted Biologic vs a Second Anti-TNF Drug to Treat Rheumatoid Arthritis in Patients With Insufficient Response to a First Anti-TNF Drug: A Randomized Clinical Trial. JAMA. 2016;316(11):1172-80.

40. Emery P, Gottenberg JE, Rubbert-Roth A, Sarzi-Puttini P, Choquette D, Taboada VM, Barile-Fabris L, Moots RJ, Ostor A, Andrianakos A, Gemmen E, Mpofu C, Chung C, Gylvin LH, Finckh A. Rituximab versus an alternative TNF inhibitor in patients with rheumatoid arthritis who failed to respond to a single previous TNF inhibitor: SWITCH-RA, a global, observational, comparative effectiveness study. Ann Rheum Dis. 2015;74(6):979-84.

41. Pawar A, Desai RJ, Solomon DH, Santiago Ortiz AJ, Gale S, Bao M, Sarsour K, Schneeweiss S, Kim SC. Risk of serious infections in tocilizumab versus other biologic drugs in patients with rheumatoid arthritis: a multidatabase cohort study. Ann Rheum Dis. 2019;78(4):456-64.

42. Sakai R, Cho SK, Nanki T, Watanabe K, Yamazaki H, Tanaka M, Koike R, Tanaka Y, Saito K, Hirata S, Amano K, Nagasawa H, Sumida T, Hayashi T, Sugihara T, Dobashi H, Yasuda S, Sawada T, Ezawa K, Ueda A, Fujii T, Migita K, Miyasaka N, Harigai M, REAL Study Group. Head-to-head comparison of the safety of tocilizumab and tumor necrosis factor inhibitors in rheumatoid arthritis patients (RA) in clinical practice: results from the registry of Japanese RA patients on biologics for long-term safety (REAL) registry. Arthritis Res Ther. 2015;17:74-015. 
43. Mori S, Yoshitama T, Hidaka T, Sakai F, Hasegawa M, Hashiba Y, Suematsu E, Tatsukawa H, Mizokami A, Yoshizawa S, Hirakata N, Ueki Y. Comparative risk of hospitalized infection between biological agents in rheumatoid arthritis patients: A multicenter retrospective cohort study in Japan. PLoS One. 2017;12(6):e0179179.

44. Rutherford Al, Subesinghe S, Hyrich KL, Galloway JB. Serious infection across biologic-treated patients with rheumatoid arthritis: results from the British Society for Rheumatology Biologics Register for Rheumatoid Arthritis. Ann Rheum Dis. 2018;77(6):905-10.

\section{Tables}

\section{TABLE 1.}

Clinical characteristics of elderly-onset RA at initiation of TNFi or IL-6i 


\begin{tabular}{|c|c|c|c|}
\hline Characteristic & $\begin{array}{l}\text { TNFi } \\
\qquad(n=674)\end{array}$ & $\begin{array}{l}\text { IL-6i } \\
\qquad(n=297)\end{array}$ & P-value \\
\hline Age, median years (IQR) & $71(67-77)$ & $72(67-77)$ & 0.34 \\
\hline Female sex, n (\%) & $513(76.1)$ & $221(74.4)$ & 0.57 \\
\hline Disease duration, median months (IQR) & $32(12-77)$ & $39(16-79)$ & 0.12 \\
\hline CRP (mg/dL), median (IQR) & $1.0(0.20-3.1)$ & $1.74(0.30-4.5)$ & 0.02 \\
\hline RF-positive, n (\%) & $452(72.6)$ & $200(73.5)$ & 0.81 \\
\hline ACPA-positive, $n(\%)$ & $396(73.1)$ & $172(74.8)$ & 0.66 \\
\hline Tender joint count, median (IQR) & $3(1-6)$ & $2(1-5)$ & 0.47 \\
\hline Swollen joint count, median (IQR) & $3(1-6)$ & $2(1-4)$ & 0.36 \\
\hline PtGA VAS (0-100mm), median (IQR) & $54(30-74)$ & $54(30-74)$ & 0.82 \\
\hline PGA VAS (0-100mm), median (IQR) & $34(19-55)$ & $35(19-54)$ & 0.99 \\
\hline DAS28-ESR, median (IQR) & $4.6(3.7-5.5)$ & $4.6(3.6-5.5)$ & 0.66 \\
\hline SDAl, median (IQR) & $17(11-25)$ & $16(10-25)$ & 0.75 \\
\hline CDAl, median (IQR) & $16(10-23)$ & $14(10-22)$ & 0.29 \\
\hline HAQ-DI, median (IQR) & $1.0(0.38-1.75)$ & $1.0(0.38-1.88)$ & 0.65 \\
\hline Concurrent methotrexate use, $\mathrm{n}(\%)$ & $417(61.9)$ & $140(47.1)$ & $<0.001$ \\
\hline Methotrexate dosage (mg/week), median (IQR) & $8(6-10)$ & $8(6-10)$ & 0.99 \\
\hline Glucocorticoid use, n (\%) & $259(38.4)$ & $141(47.4)$ & 0.009 \\
\hline Glucocorticoid dosage (mg/day), median (IQR) & $5.0(3.0-7.0)$ & $5.0(4.0-8.0)$ & 0.52 \\
\hline Sulfasalazine use, $\mathrm{n}(\%)$ & $152(22.6)$ & $70(23.6)$ & 0.74 \\
\hline Other csDMARDs use, $\mathrm{n}(\%)$ & $110(16.4)$ & $73(24.8)$ & 0.003 \\
\hline $1^{\text {ST }}$ bDMARD (\%) & $430(63.8)$ & $127(42.8)$ & $<0.001$ \\
\hline $2^{\text {nd }}$ bDMARD (\%) & $164(24.3)$ & $88(29.6)$ & 0.12 \\
\hline${ }^{3} 3^{\text {rd }}$ bDMARD $(\%)$ & $80(11.9)$ & $82(27.6)$ & $<0.001$ \\
\hline
\end{tabular}

Data are no. (\%) patients or median IQR

Demographic and clinical characteristics at initiation of TNFi or IL-6i summarized as median for continuous data and as numbers (percentages) for categorical data. T-test or Wilcoxon signed-rank test Loading [MathJax]/jax/output/CommonHTML/jax.js are the clinical characteristics between the 2 groups for 
continuous variables and categorical variables, respectively. ACPA anti-citrullinated protein antibodies, bDMARDs biological disease-modifying antirheumatic drugs, csDMARDs conventional synthetic DMARDs, CDAI clinical disease activity index, CRP C-reactive protein, DAS28-ESR Disease Activity Score 28-erythrocyte sedimentation rate, EORA elderly-onset rheumatoid arthritis, IL-6i Interleukin-6 Inhibitors, HAQ-DI Health Assessment Questionnaire Disability Index, PtGA patient global assessment, PGA physician global assessment, RF rheumatoid factor, SDAl simplified disease activity index, TNFi Tumor Necrosis Factor inhibitors, YORA young-onset rheumatoid arthritis, VAS visual analogue scale

\section{Figures}

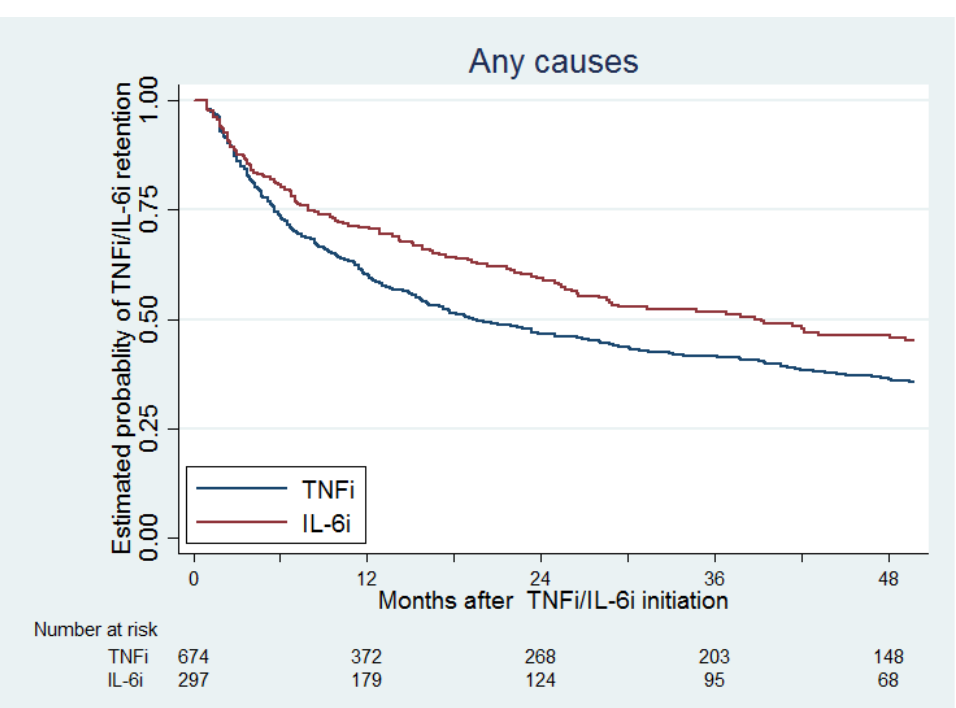

A

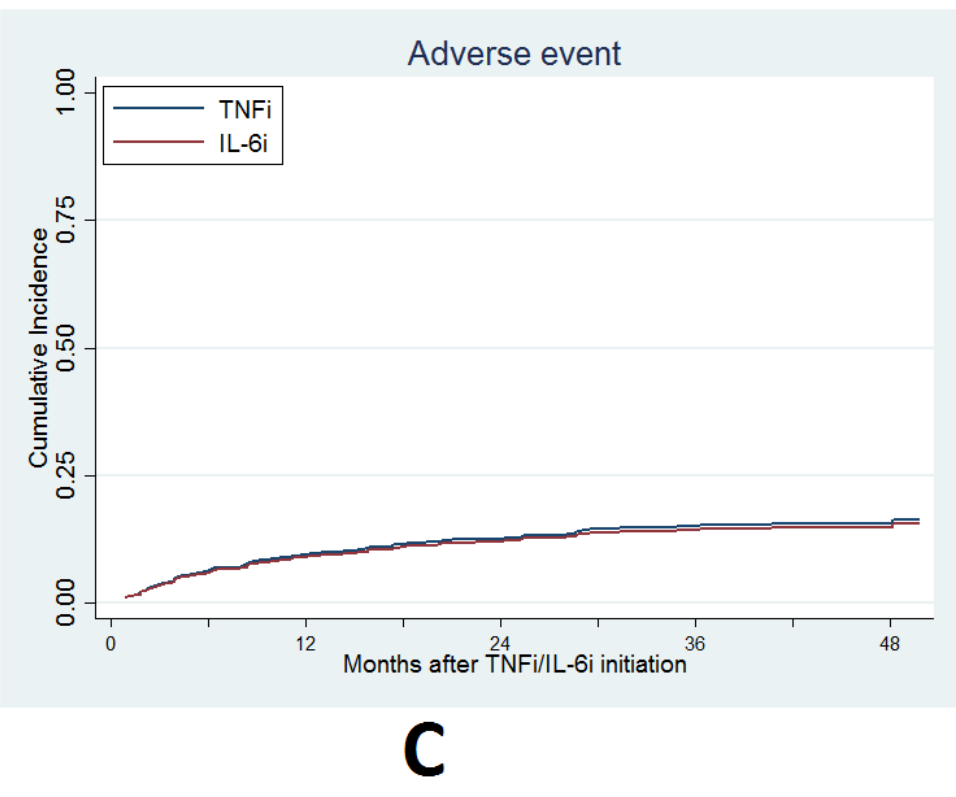

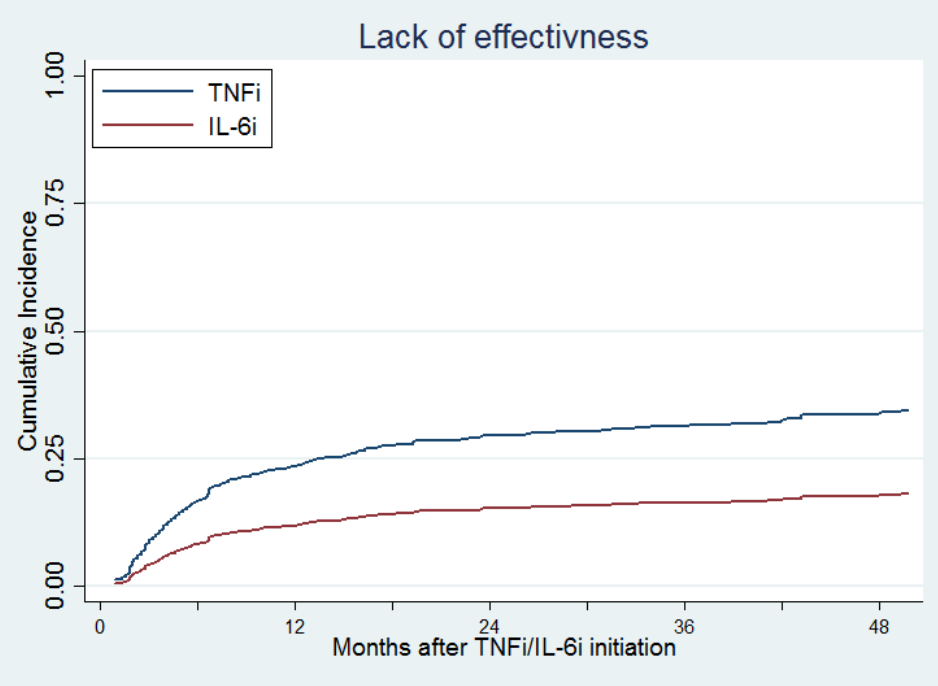

B

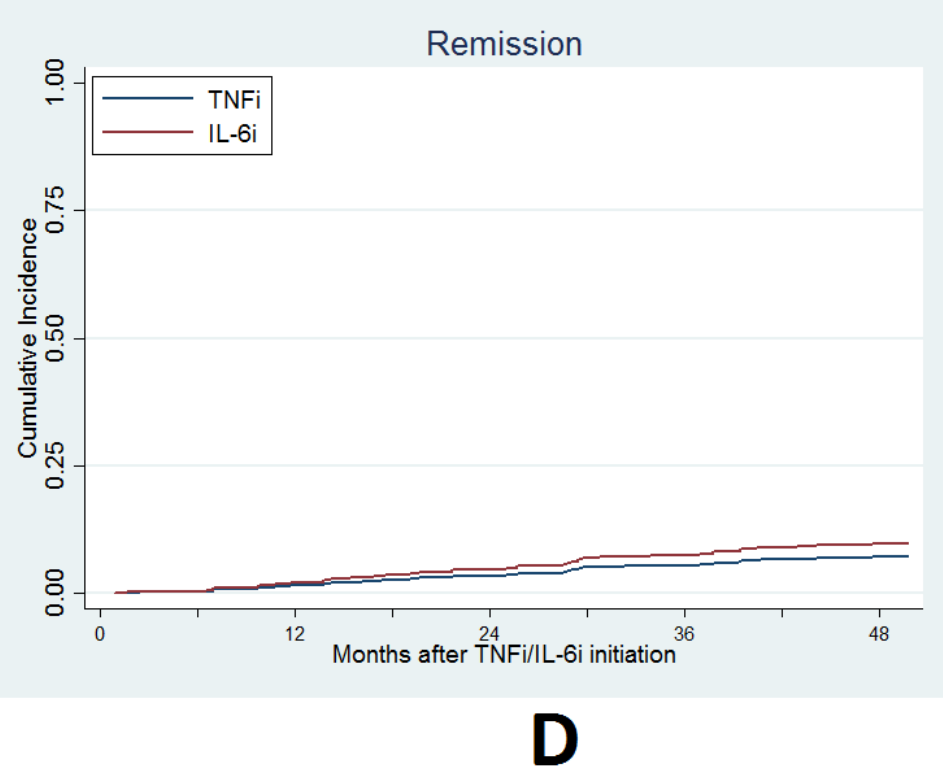

Figure 1 
Adjusted drug retention and adverse event among TNFi and IL-6i patients TNFi= Tumor Necrosis Factor inhibitors, IL-6i= Interleukin-6 Inhibitors A. Adjusted drug retention between TNFi and IL-6i B. Adjusted cumulative incidence of drug discontinuation due to lack of effectiveness between TNFi and IL-6i C. Adjusted cumulative incidence of drug discontinuation due to adverse event between TNFi and IL-6i D. Adjusted cumulative incidence of drug discontinuation due to remission between TNFi and IL-6i
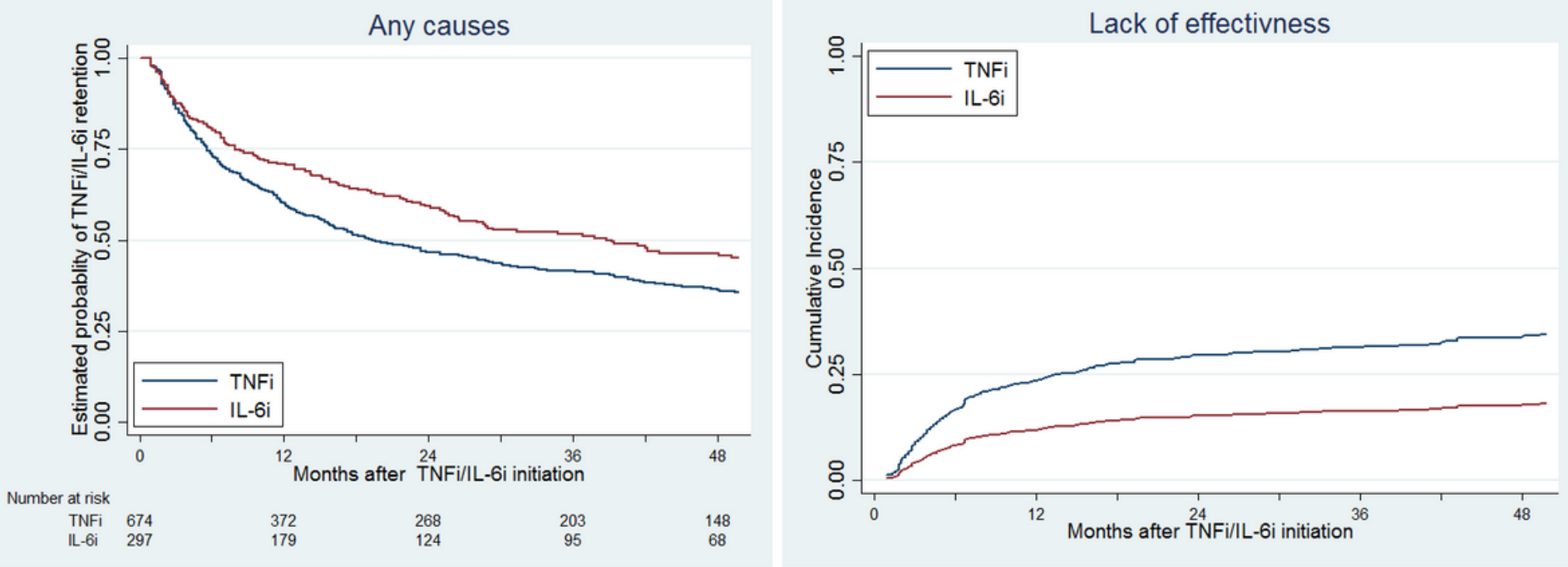

A
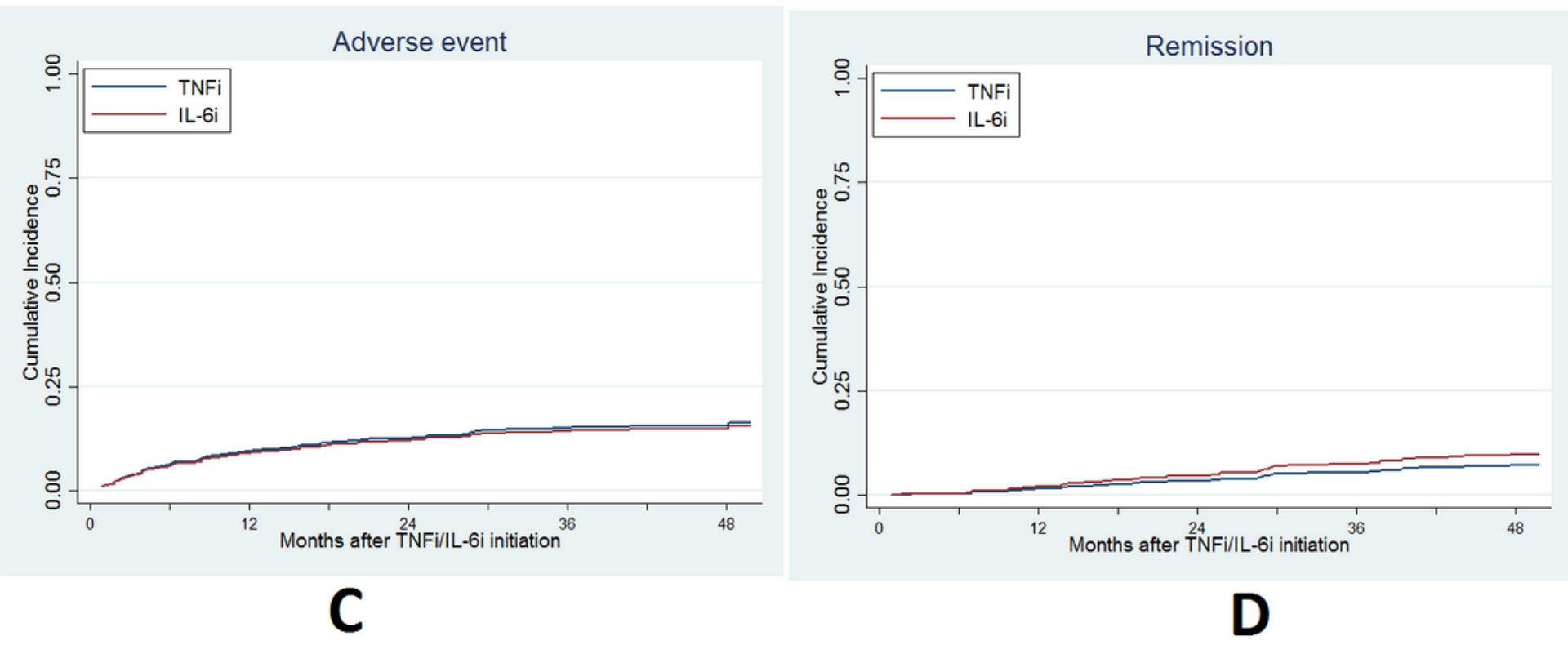

\section{Figure 1}

Adjusted drug retention and adverse event among TNFi and IL-6i patients TNFi= Tumor Necrosis Factor inhibitors, IL-6i= Interleukin-6 Inhibitors A. Adjusted drug retention between TNFi and IL-6i B. Adjusted cumulative incidence of drug discontinuation due to lack of effectiveness between TNFi and IL-6i C. Adjusted cumulative incidence of drug discontinuation due to adverse event between TNFi and IL-6i D. Adjusted cumulative incidence of drug discontinuation due to remission between TNFi and IL-6i 